\title{
Veridicção e paixão na práxis enunciativa
}

Arnaldo Cortina

\section{Resumo}

O propósito deste trabalho consiste em mostrar a perspectiva metodológica da teoria semiótica para o tratamento da questão do discurso. Focalizando especificamente os conceitos de veridicção e de paixão, procura observar como fazem parte do processo de constituição da práxis enunciativa. Para o exame desses dois procedimentos discursivos serão comentados, a título de exemplo da metodologia de análise, dois textos distintos, um conto de Machado de Assis intitulado "O cônego ou a metafísica do estilo" e um texto publicitário da cerveja Nova Schin, publicado em revista semanal de notícias.

Palavras-chave: Enunciação. Paixão. Práxis enunciativa. Texto. Veridicção. 


\section{Texto e discurso na teoria semiótica: construção do método}

Dentre as várias acepções atribuídas ao termo texto, Greimas e Courtés (2008) consideram que, segundo Hjelmslev (1975), o texto designa "a totalidade de uma cadeia linguística, ilimitada em decorrência da produtividade do sistema" (p.503). Por outro lado, o termo texto pode ser empregado em sentido restritivo: "isso se dá quando a natureza do objeto escolhido (a obra de um escritor, um conjunto de documentos conhecidos ou de depoimentos recolhidos) marca-lhe os limites; nesse sentido, texto se torna sinônimo de corpus" (p.503). Tanto num sentido quanto no outro, o texto designa uma grandeza considerada anteriormente à sua análise. Assim, pode-se perceber que "o texto se constitui apenas de elementos semióticos conformes ao projeto teórico da descrição" (p. 503), isto é, dependente do foco a partir do qual se observa o material textual.

Para muitas teorias, o discurso pode ser considerado equivalente ao texto, mas quando se observa a proposta teórico-metodológica da semiótica, o discurso deve ser entendido como uma instância do percurso gerativo de sentido, correspondente ao enunciado, em que se manifestam o enunciador e o enunciatário, num tempo e num espaço, quando se aborda a sua organização sintática, em que aparecem temas e figuras, no componente semântico.

Falar, portanto, do texto e do discurso segundo a perspectiva semiótica significa observar um objeto a partir do ponto de vista de uma teoria que se preocupa com a apreensão do sentido do texto e que, a partir do exame desse objeto, descreve seu sentido, geralmente elegendo-se um ponto de vista específico, na medida em que considera impossível a descrição global do sentido, sem que se possa, a partir de determinada posição, reexaminá-lo e perceber outras variações.

É interessante observar que, no decorrer das investigações da questão da significação, mais especificamente no caso dos trabalhos de pesquisadores franceses, a semiótica distingue-se da semiologia. Enquanto esta última adota uma interpretação linguística do signo, nas suas mais diferentes formas de manifestação (o que é realizado por Barthes e Jakobson), aquela, a semiótica, opta por examinar, uma por uma, as diferentes formas de manifestação do signo (quer verbais, quer não-verbais) sem tratá-los metaforicamente como espécies de linguísticas.

Nesse sentido, portanto, tomo partido neste trabalho da visão da semiótica que parte de um objeto, o texto, qualquer que seja sua materialidade, para examiná-lo, por meio da aplicação de um método em que se apresentam tensões, contradições, continuidades e descontinuidades e um percurso de geração de seu sentido. 
Assim, a semiótica define-se como uma teoria geral da significação, como uma teoria da linguagem. Não uma teoria particularmente linguística, embora sua herança o seja. Ao propor uma descrição da significação em níveis, constitui um modelo de previsibilidade comum a textos verbais, não-verbais e sincréticos, que têm seu processo de textualização descrito por semióticas específicas.

Originalmente a semiótica preocupa-se com a delimitação de um objeto homogêneo, com a construção de um modelo de análise de cunho hipotético-dedutivo, com a construção de um modelo para descrever a universalidade da significação, sempre visando a um rigor metodológico. Entretanto, com seus diferentes desdobramentos, deve ser considerada como uma teoria não acabada, um projeto teórico que vai, na sua trajetória, desenvolver seu corpo de conceitos e estender os domínios de sua reflexão de modo a abranger, sucessivamente, aspectos da significação a que renunciou, inicialmente, em nome de um princípio de homogeneidade.

As mudanças teóricas mais acentuadas dos últimos anos têm levado à consideração de fases da Semiótica. Hénault (2006) fala de três períodos de síntese da transformação dos estudos em semiótica. O primeiro inicia-se com a publicação de Semântica estrutural, de Greimas, obra fortemente influenciada pelos trabalhos de Hjelmslev e BrØndäl, cujas abundantes análises sêmicas apresentadas abriram amplas perspectivas para os estudos literários e para as pesquisas em lexicologia. A segunda síntese diz respeito a uma série de artigos publicados por Greimas entre 1966 e 1979. Esse período, segundo a autora, foi de intensa reavaliação epistemológica, pois a descoberta da proposta de análise narrativa de Propp é investigada e transformada segundo a perspectiva de uma semiótica que assumia a dimensão transfrástica. Além disso, o "desenvolvimento da problemática das modalidades marca época na história da semiótica, uma vez que ela, por sua vez, permitia fragmentar em percursos actantes mais precisos, os programas de fazer ou de ser que tinham permitido articular e decompor as grandes unidades que eram as provas do esquema canônico" (p. 141). A terceira síntese, segundo a autora, consiste na publicação do Dicionário de Semiótica em 1979, que parecia fixar e definir mais claramente todos os conceitos até então utilizados pelos pesquisadores em semiótica e se estende até 1991, ano de publicação do livro Semiótica das paixões, em co-autoria de Greimas e Fontanille.

Hénault (2006) termina seu texto com a constatação de que, a partir de certo momento, a pretensa estabilidade almejada com a publicação do dicionário deu lugar a uma série de insatisfações tendo em vista os diferentes trabalhos que então estavam sendo desenvolvidos por diferentes semioticistas reunidos em torno de Greimas nas sessões dos "Seminários de semiótica”, de Paris. Esse período das três sínteses apontadas pela autora costuma ser 
designado então como período da semiótica clássica. A partir da morte de Greimas, em 1992, as novas tendências dos estudos em semiótica disputam um lugar na sucessão de seus trabalhos. Zilberberg desenvolve sua proposta de uma semiótica tensiva; Fontanille, a semiótica da práxis enunciativa; Landowski, a sociossemiótica; Coquet, a semiótica subjetal; Petitot, a semiótica morfodinâmica, entre outras. Essas diferentes formas de abordagem da significação em alguns momentos parecem desagregar e fracionar uma postura teórica mais coesa; por outro lado, porém, são também sua força, porque permitem observar a complexidade do processo de constituição da significação em múltiplos objetos.

\section{Primeira abordagem dos procedimentos enunciativos}

Na década de 1970, quando Greimas veio ao Brasil para ministrar um curso de semiótica a um grupo de pesquisadores engajados em compreender suas propostas metodológicas e interessados em contribuir para seu desenvolvimento, houve, em certo dia, uma pergunta a ele dirigida por Edward Lopes e Ignácio Assis Silva a propósito da enunciação. A resposta de Greimas acabou sendo publicada na forma de um artigo, com título "A enunciação (uma postura epistemológica)", no número um, de 1974, da revista Significação, editada pelo Grupo de Estudos Semióticos "Algirdas Julien Greimas", que foi fundado exatamente durante aquele curso em Ribeirão Preto, no interior paulista. Como afirma Greimas em seu texto, não se tratava de uma pergunta, mas de um conjunto de perguntas que indagava sobre a relação entre enunciado e enunciação.

Não é meu propósito aqui retomar toda a problemática então tratada, mas destacar um dos aspectos desse conjunto de questões. Ele diz respeito à indagação proposta por Lopes eSilva a respeito da possibilidade de interpretar a relação entre enunciação e enunciado como um processo metalinguístico. De fato, Greimas afirma essa possibilidade ao dizer que a enunciação é o próprio enunciado, pois, mesmo que não aponte marcas mais explícitas, é sempre pressuposta, isto é, não se pode conceber o enunciado sem se reportar à enunciação.

E por que começar então com essa lembrança? Por que ao me deparar com essa temática reporto-me à questão da metalinguagem? A razão está no fato de que, para falar de veridicção e de paixão, é necessário fazer referência à instância da enunciação no discurso. E na medida em que proponho refletir sobre essa questão, estarei tratando de um mecanismo que é intrínseco ao próprio texto que produzo.

Para iniciar, portanto, a discussão, partirei de duas citações de dois diferentes textos que apresentam uma definição para veridicção e outra para a paixão, a partir do ponto de vista designado por Hénault (2006), acima referido, como semiótica clássica. 
Segundo Greimas e Courtés (2008), no que se refere ao ato comunicativo, o que interessa observar, do ponto de vista semiótico, não é o problema da verdade, mas o do dizer verdadeiro, isto é, o da veridicção. Assim, entre destinador e destinatário ou entre enunciador e enunciatário do processo comunicativo "um crer-verdadeiro deve ser instalado [...] e é esse equilíbrio, mais ou menos estável, esse entendimento tácito entre dois cúmplices mais ou menos consciente que nós denominamos contrato de veridicção (ou contrato enunciativo)" (p. 530). Dessa forma, portanto, o que os autores apontam é que a semiótica deve estar atenta para a maneira como o discurso constrói seu efeito de verdade.

Em outro texto, Greimas afirmava o seguinte:

[...] o discurso é esse lugar frágil em que se inscrevem e em que se leem a verdade e a falsidade, a mentira e o segredo; esses modos de veridiç̧ão resultam da dupla contribuição do enunciador e do enunciatário, essas diferentes posições fixam-se apenas sob a forma de um equilíbrio mais ou menos estável, proveniente de um acordo implícito entre dois actantes da estrutura da comunicação. É esse entendimento tácito que é designado pelo nome de contrato de veridiçção. (GREIMAS, 1983, p.105. Tradução nossa e grifo do autor).

Para a semiótica, portanto, todo discurso é o resultado da negociação de um sentido entre sujeitos, o que se estabelece por meio da veridicção.

Com relação às paixões, Greimas e Fontanille irão afirmar que elas aparecem no discurso como portadoras de efeitos de sentido muito particulares. Esses efeitos constituem-se num "perfume" difícil de determinar, mas que emana da organização discursiva das estruturas modais. Segundo os autores, compreender as paixões como perfume remete a duas constatações.

Uma primeira constatação impõe-se: a sensibilização passional do discurso e sua modalização narrativa são co-ocorrentes, não se compreende uma sem a outra, e, no entanto, são autônomas, submissas, provavelmente, ao menos em parte, a lógicas diferentes. [...] Em segundo lugar, captar os efeitos de sentido globalmente como 'cheiro' dos dispositivos semionarrativos postos em discurso é reconhecer, de certa maneira, que as paixões não são propriedades exclusivas dos sujeitos (ou do sujeito), mas propriedades do discurso inteiro, e que elas emanam das estruturas discursivas pelo efeito de um 'estilo semiótico' que pode projetar-se seja sobre os sujeitos, seja sobre os objetos, seja sobre sua junção. (GREIMAS; FONTANILLE, 1993, p.21)

O que se pode observar nessas citações, portanto, é que tanto a veridicção quanto a paixão correspondem a efeitos de sentido do discurso. Por outro lado, porém, ao mesmo tempo em que essas relações são estabelecidas na superfície discursiva, podem ser identificadas no nível das estruturas narrativas - e foi desse nível que Greimas e seus seguidores partiram inicialmente. Embora o conceito de veridicção tenha emanado do exame das modalidades 
1 Trata-se aqui de referência ao quadrado semiótico proposto por Greimas com o objetivo de tornar operatória a representação da estrutura elementar da significação. Os dois eixos da contrariedade são constituídos por dois termos positivos contrários e dois termos negativos subcontrários. Além disso, representam-se no quadrado as relações de contradição, que é elaborada por um esquema positivo e por um esquema negativo, e ainda a de complementariedade, que se estabelece por meio de uma dêixis positiva e outra negativa. veridictórias observadas no nível narrativo em que, por exemplo, o destinador, para manipular seu destinatário, vale-se da mentira (parecer + não-ser), do segredo (não-parecer + ser), da falsidade (não-parecer + não-ser) ou da verdade (parecer + ser) e, por desdobramento, alçado ao nível discursivo, o conceito de paixão levou um certo tempo para se incorporar às análises discursivas no desenrolar das propostas metodológicas da semiótica.

Embora Greimas e Fontanille (1993) abram o capítulo "A epistemologia das paixões" com o trecho acima reproduzido, as análises da avareza e do ciúme desenvolvidas nos capítulos seguintes centram-se nas paixões de papel, isto é, na maneira como a avareza ou o ciúme manifesta-se no enunciado.

Com relação ao capítulo sobre a avareza, dois textos são citados para discutir essas paixões: a fábula de La Fontaine, "A leiteira e a bilha de leite", e um trecho do romance de Balzac, As ilusões perdidas, que focaliza a atitude avara de Mme. Bargeton quando se vê obrigada a sobreviver com o dinheiro que havia trazido consigo para viver em Paris.

No caso da fábula de La Fontaine, o que se pergunta é se a narrativa trata do "investimento" ou da "dissipação", duas dêixis do quadrado ${ }^{1}$ que representam a oposição entre "tomar" e "dar", correspondentes às ações decorrentes das paixões da "avareza" e da "dissipação". Na realidade, o que o discurso manifesto nessa história aponta é o fazer do sujeito central, a menina. Ao se distrair com seus pensamentos que consistiam no acúmulo de valor, de bens, e consequente enriquecimento, a garota não realiza adequadamente o percurso do transporte da bilha de leite. Ao tropeçar, deixa cair a bilha, o que significa a impossibilidade de realizar tudo o que imaginara fazer com a venda do leite. A moral que encerra a fábula chama a atenção para a distração da menina: ao invés de ficar sonhando com o que poderia ser, deveria ter mais atenção com o que tinha de fazer. Essa contraposição modal é dirigida ao enunciatário e a narrativa corresponde à figurativização do não-dever-fazer.

No caso do texto de Balzac, aponta-se uma oposição de valores. A parcimônia de Mme. Bargeton com seus gastos em Paris é interpretada como avareza pelas pessoas que vivem naquela cidade, pois elas são caracterizadas pela dissipação. Já na cidade do interior francês de onde tinha vindo, Angoulême, sua atitude era comum à de todos os nobres da região, que consistia na moderação dos gastos. Enquanto exame da manifestação passional do texto de Balzac, o que essas observações de Greimas e Fontanille (1993) apontam é que a caracterização da paixão depende do contexto em que se manifesta, pois é uma questão de valor.

Em Cortina (2004) procurei mostrar a análise de dois textos tipologicamente distintos com o objetivo de discutir duas perspectivas para o tratamento da paixão. No conto "A desejada das gentes", de Machado de Assis, ela é vista como elemento consti- 
tuinte da narrativa e na crônica jornalística "Ereção permanente", de Mario Vargas Llosa, como manifestação retórica da organização discursiva. A principal preocupação desse trabalho consistiu em contrapor o exame de uma paixão de papel, a obsessão do narrador pela bela Quintília, presente no conto machadiano, à análise da enunciação apaixonada do enunciador da crônica de Llosa, ao relatar sua experiência de conhecer o carnaval brasileiro.

No caso do texto de Machado, verifica-se que a paixão é o que move a narrativa que é contada por um sujeito a outro, em segundo plano. A técnica do narrador consiste em diluir sua presença para dar voz a duas personagens que conversam, o que vem a ser a debreagem de segundo grau. Uma delas, o conselheiro, conta a seu amigo o que se passou em determinada época de sua vida, constituindo-se, assim, num narrador de segunda instância, pois sua narrativa se dá no interior da debreagem de segundo grau. O conto de Machado simula a situação de uma peça de teatro em que as personagens falam. O leitor é um espectador que assiste ao drama.

No caso do texto da crônica jornalística, a dimensão passional pode ser identificada na maneira a partir da qual o enunciador se relaciona com o tema do discurso que produz. Ao relatar sua experiência de presenciar as festividades do carnaval carioca o enunciador demonstra estar envolvido com aquilo que narra, pois sua visão sobre o acontecimento é eufórica. Nesse sentido, seu fazer argumentativo consiste em despertar no leitor a mesma paixão, isto é, modalizá-lo pelo querer. As marcas de subjetividade presentes no discurso de Llosa são também uma forma de aproximação de seu leitor, o que corrobora o princípio passional de sua construção.

Quanto ao aspecto do valor que adquire a dimensão passional, o que se pode constatar por meio do exame dos dois textos acima referidos é que eles se projetam de forma diferenciada. Enquanto o de Machado constrói um cenário em que a relação entre sujeito e objeto reflete uma tensão entre um querer e um não-poder, que delimitam e confrontam o desejo, pois o narrador da história interna do conto não consegue obter a aceitação de seu amor por Quintília, o de Llosa descreve um cenário em que o desejo não tem limites, é distenso, e em que o querer e o poder não se opõem, pois a relação verdadeira é a da complementaridade.

Não se pode deixar de notar, porém, que no texto machadiano há uma transformação do querer que move os sujeitos da história. Inicialmente o interesse do herói por Quintília decorre de uma aposta, pois ela era objeto de interesse de vários homens que cobiçavam suas posses, mas, com a aproximação entre os dois ocorre uma transformação de estados: ao invés de ser movido pelo interesse, ele passa a ser movido pela paixão. De acordo com a análise proposta, a transformação do estado de relaxamento para o de tensão na trama amorosa do conto machadiano se dá em 
função do apagamento do valor econômico do objeto do desejo, isto é, os dois amigos que haviam feito a aposta deixam de caracterizar Quintília como objeto da riqueza e passam a valorizá-la enquanto sujeito.

O que é possível dizer ainda sobre esses textos, do ponto de vista da veridicção, é que cada um deles se vale de um recurso distinto para criar o efeito de sentido de verdade. $\mathrm{O}$ conto de Machado, como já apontamos acima, vale-se da manifestação do diálogo como forma de representação do fato narrado. $\mathrm{O}$ conselheiro e seu amigo encontram-se e o primeiro conta para o segundo como conheceu e como se apaixonou pela bela Quintília. A reconstituição dessa situação de interlocução é responsável pela manutenção da impressão da realidade do relato. A crônica de Llosa, por sua vez, mantém o efeito de verdade, porque euforicamente o enunciador afirma que viveu a situação que narra ao vir ao Rio de Janeiro para conhecer o carnaval e que isso tinha sido uma experiência inusitada.

Partindo, portanto, da visão clássica da semiótica sobre veridicção e paixão, procurei contrapor à manifestação da paixão de papel, que faz parte da estratégia veridictória de um texto no nível de seu enunciado, como é o caso do conto de Machado acima referido, a manifestação da paixão como estratégia veridictória de outro texto, o de Llosa, no nível da enunciação. Resta então examinar como essa mesma questão pode ser observada a partir dos desenvolvimentos mais recentes da semiótica oriunda da obra greimasiana.

\section{Segunda abordagem dos procedimentos enunciativos}

Diferentemente da concepção estrutural de que se originou a semiótica, a questão da enunciação passa a ser observada a partir de uma outra perspectiva. A significação deixa de ser pura e simplesmente um artefato resultante de uma série de combinações do sistema da língua e é compreendida como o reflexo da movimentação desse sistema com o contexto em que é produzida. Nesse sentido, o ideológico é reconhecido como intrínseco à significação, porque determina e é determinado pelo uso da língua. Retomando Hjelsmlev (1975), a interdependência entre uma forma do conteúdo e uma forma da expressão é o que constitui exatamente a linguagem e é isso que fará com que ela construa sentidos.

Dessa maneira, portanto, é que os estudos mais recentes da semiótica irão pensar uma práxis da enunciação. Não se trata, portanto, de descrever o mecanismo dos elementos do discurso no percurso gerativo do sentido, mas de entender de forma dinâmica as interligações entre os diferentes patamares que o constituem. Assim, a enunciação não está simplesmente acoplada às instâncias sêmio-narrativas, mas determina-as e, por elas, é determinada. 
Reconhecer, porém, a inter-relação entre o enunciado e suas condições de produção não significa afirmar o primado da verdade sobre o dizer. Um texto nunca será a expressão de uma realidade concreta, porque a linguagem é a mediadora entre o real e uma forma de apreendê-lo, ela não é uma instância reprodutora, mas criadora. Assim, quando se pensa na constituição do sentido pela linguagem, pensa-se na veridicção e não na verdade. A interpretabilidade do texto está assentada na forma como ele se faz parecer verdadeiro, isto é, como entre enunciador e enunciatário é negociado o dizer verdadeiro. Além disso, nessa relação entre enunciador e enunciatário está sempre pressuposta a ideia de um contrato, de uma adesão, o que implica que o primeiro age sobre o segundo por meio de um procedimento retórico-discursivo que é a passionalização.

Para procurar tornar mais clara essa questão dos procedimentos veridictórios e passionais na constituição da práxis enunciativa, examinemos dois diferentes textos, que se constroem a partir de duas diferentes semióticas: a verbal e a visual. O primeiro deles é o conto machadiano intitulado "O cônego ou a metafísica do estilo" (ASSIS, 1997, p. 570-3), publicado originalmente no livro de contos intitulado Várias histórias.

Em primeiro lugar, o que se deve considerar quando se examina a constituição significativa do texto de Machado é que ele, primeiramente, obedece às injunções da linguagem escrita e, além disso, corresponde a um tipo específico de texto, o conto, que é uma das formas da manifestação da linguagem literária. Nesse sentido, a práxis enunciativa está condicionada a um conceito que Fontanille (2007) retoma de Iuri Lotman e procura incorporá-lo à semiótica, qual seja, o de semiosfera. Assim, a forma de construção do enunciado reflete uma concepção cultural do tipo de texto a ser produzido.

Uma característica central da narrativa machadiana é o diálogo entre o narrador e seu narratário. Toda a história é contada como se o narrador estivesse diante de seu narratário e a ele contasse um caso. E o conto cria um efeito tão verídico desse diálogo que é um dos poucos textos em que o leitor tem voz, pois a ele são atribuídos três enunciados: "Sexual?"; "Mas, então, amam-se umas às outras?"; "Confesso que não." (ASSIS, 1997, p. 571). O próprio título sugere esse caráter dialógico, ao coordenar dois sintagmas por meio da conjunção alternativa "ou", pois sugere que o leitor pode escolher um deles para direcionar a leitura da narrativa. O conto pode chamar-se "o cônego" ou "metafísica do estilo", porque, ao contar a história de um cônego que escreve um sermão, faz uma discussão sobre o estilo de sua escrita. Cada um desses títulos corresponde a uma narrativa distinta. A primeira é aquela que conta como o cônego recebeu o convite para escrever seu sermão e como se pôs a produzi-lo. A segunda é a que narra 
a história de uma palavra que procura por outra para construir o discurso. $\mathrm{O}$ recurso utilizado pelo enunciador para construir a narrativa da produção do sermão é o da intertextualidade.

O conto inicia-se por meio da reprodução de um diálogo entre um casal apaixonado, duas palavras que se procuram, um substantivo e um adjetivo. Ocorre, porém, que o dizer atribuído a cada um dos apaixonados é a reprodução do enunciado do "Cântico dos cânticos", do Velho Testamento. Por meio do emprego das aspas, o que caracteriza, na perspectiva dos trabalhos de AuthierRevuz (1998), um procedimento de heterogeneidade mostrada marcada, o dizer de um ("Vem do Líbano, esposa minha, vem do Líbano" - reprodução de dois versos do $3^{\circ}$ canto) é seguido pelo dizer do outro ("Eu vos conjuro, filhas de Jerusalém, que se encontrardes o meu amado, lhe façais saber que estou enferma de amor..." - reprodução de três versos do $4^{\circ}$ canto).

Na realidade, a narrativa do conto machadiano simula o ato de produção do discurso. A estrutura que dá suporte à narração é bastante simples. O cônego Matias $\left(\mathrm{S}_{1}\right)$ fora convidado por algumas pessoas $\left(\mathrm{S}_{2}\right)$ a escrever o sermão para uma festa. Inicialmente recusa o convite, mas é convencido a realizar a tarefa quando $\mathrm{S}_{2}$ alude a sua competência para compor o sermão (faria aquilo brincando). Assim, seduzido pelo Destinador-manipulador, $\mathrm{S}_{1}$ põe-se a executar a tarefa. O narrador da história dirige-se, então, ao leitor e convida-o a entrar na mente do cônego para ver como ele elaborava seu sermão. Percebe-se, portanto, que a um procedimento de manipulação manifestado no enunciado há outro correlato na enunciação.

Porque não tinha muita disposição para escrever, Matias inicia seu sermão com má vontade, mas começa a tomar gosto pelo trabalho e mergulha na construção do texto. Ora escrevendo com mais velocidade, à medida que as palavras fluem na continuidade do discurso, ora diminuindo o ritmo, quando precisa escolher com mais vagar as palavras que irá empregar, Matias, de repente, cai num estado de falta: precisa escolher um adjetivo adequado para combinar com um substantivo, mas o termo apropriado não lhe vem à mente. Essa tensão desencadeada pela ausência do termo que combinaria com outro é narrada de forma alegórica pelo narrador que toma o leitor pelas mãos e convida-o a penetrar no cérebro do cônego. Em verdade o substantivo (Ś́lvio) que habita o lado direito do cérebro sai à procura de seu par, o adjetivo (Sílvia), que habita o lado esquerdo. A intensidade da procura é marcada pela extensão da busca de um pelo outro. Pode-se ainda fazer uma inferência interpretativa, que a cena narrada sustentaria, em relação ao nome do amado e da amada. Sílvio, na mitologia latina, é o filho de Enéas e Lavínia, que nascera em um bosque; consequentemente, Sílvia é sua forma feminina e significa aquela que é nascida na floresta. A mata, ou o bosque, ou a floresta, cor- 
responde à figurativização do cérebro de Matias, lugar do qual surgem Sílvio e Sílvia que buscam um encontro.

O procedimento da intertextualidade, então, já anunciado anteriormente, consiste em que os dizeres dos sujeitos apaixonados trazem para o texto de Machado trechos do texto do "Cântico dos cânticos" bíblico. Em contraposição a esse texto há referência ao texto shakespeariano, também pelo procedimento da intertextualidade ("Julieta é o sol... ergue-te, lindo sol"). Essa oposição marcada pelo enunciador aponta para o caráter do interdiscurso. No cérebro de Matias, um eclesiástico, o diálogo amoroso só poderia manifestar-se por meio da reprodução do discurso bíblico, pois sua visão do amor entre dois seres só pode ser mediada pela visão bíblica da paixão, por isso "Cântico dos cânticos" e não "Romeu e Julieta", de Shakespeare, que fala do amor mundano.

Observa-se, portanto, no nível da manifestação, um diálogo entre diferentes posições de discursos, que são invocadas por meio da instância da enunciação, para caracterizar o dizer do sujeito responsável pela transformação narrada, qual seja, a produção de um sermão em comemoração a uma festividade. E essa voz enunciativa, num afirmar metalinguístico reiterado, considera o casamento entre as palavras, fruto da união entre Sílvio e Sílvia que se procuram, a própria definição do estilo. Ao responder a uma pergunta do leitor que se admira pela revelação de que as palavras nutrem um sentimento amoroso entre elas, o narrador responde: "Amam-se umas às outras. E casam-se. O casamento delas é o que chamamos estilo." Assim, no dizer do enunciador, ao construir seu texto, cônego Matias realiza um encontro entre duas palavras que estão em seu cérebro e a possibilidade desse encontro aí realizado será responsável pela configuração individual do seu dizer, uma maneira de tornar particular a forma de reproduzir um discurso outro, no caso, o religioso.

De qualquer forma é preciso também observar que a instauração da práxis enunciativa no texto machadiano é decorrente de uma circunstância da semiosfera, uma vez que se deve levar em consideração que se trata de um texto literário e, dentre os diferentes tipos de textos dessa modalidade, é um conto. Partindo desse dado é possível observar que a relação entre o enunciador e seu enunciatário é marcada por um movimento de tensão crescente que sustenta o jogo entre essência e aparência em que se assenta o contrato veridictório. Entre a narrativa da busca de Sílvio por Sílvia que ocorre na mente do cônego há uma diferença de aceleração em relação àquela que conta o ato da escrita do sermão. Enquanto a primeira segue um movimento frenético, que é a busca do amado e da amada, a segunda é lenta, pois, para escrever, o cônego se põe a pensar e seu estado de reflexão é marcado pela distensão, pela acomodação.

Ao mesmo tempo em que esses dois percursos desenvolvemse, há ainda a constituição da narrativa englobante, responsável 
pelo desenvolvimento das duas anteriores. Ela é a conversa entre dois interlocutores, o sujeito que enuncia e o sujeito para quem se dirige. Essa complexidade discursiva configura a práxis enunciativa do texto machadiano. Seu valor literário reside no fato de que há um efeito estético criado pelo jogo entre um conteúdo e uma forma responsável pelo acabamento do texto. Além disso, o fato de ser uma história mais curta e mais centrada em um único foco (a escrita de um sermão realizada por um cônego), o que a caracteriza como conto, é o que determina a manutenção da tensão da significação no texto.

A configuração enunciativa do conto de Machado, portanto, compõe-se por meio do jogo entre o contrato veridictório instaurado entre enunciador e enunciatário e a manifestação passional. Ao mesmo tempo em que há uma paixão enunciada, revela-se uma paixão na enunciação.

Examinemos agora outro texto, constituído a partir de outra semiótica, a visual. Na verdade, o texto em questão estabelece uma inter-relação entre a semiótica visual e a verbal, o que o caracteriza como um texto sincrético. Trata-se de uma propaganda da cerveja Nova Schin, veiculada em uma revista semanal.

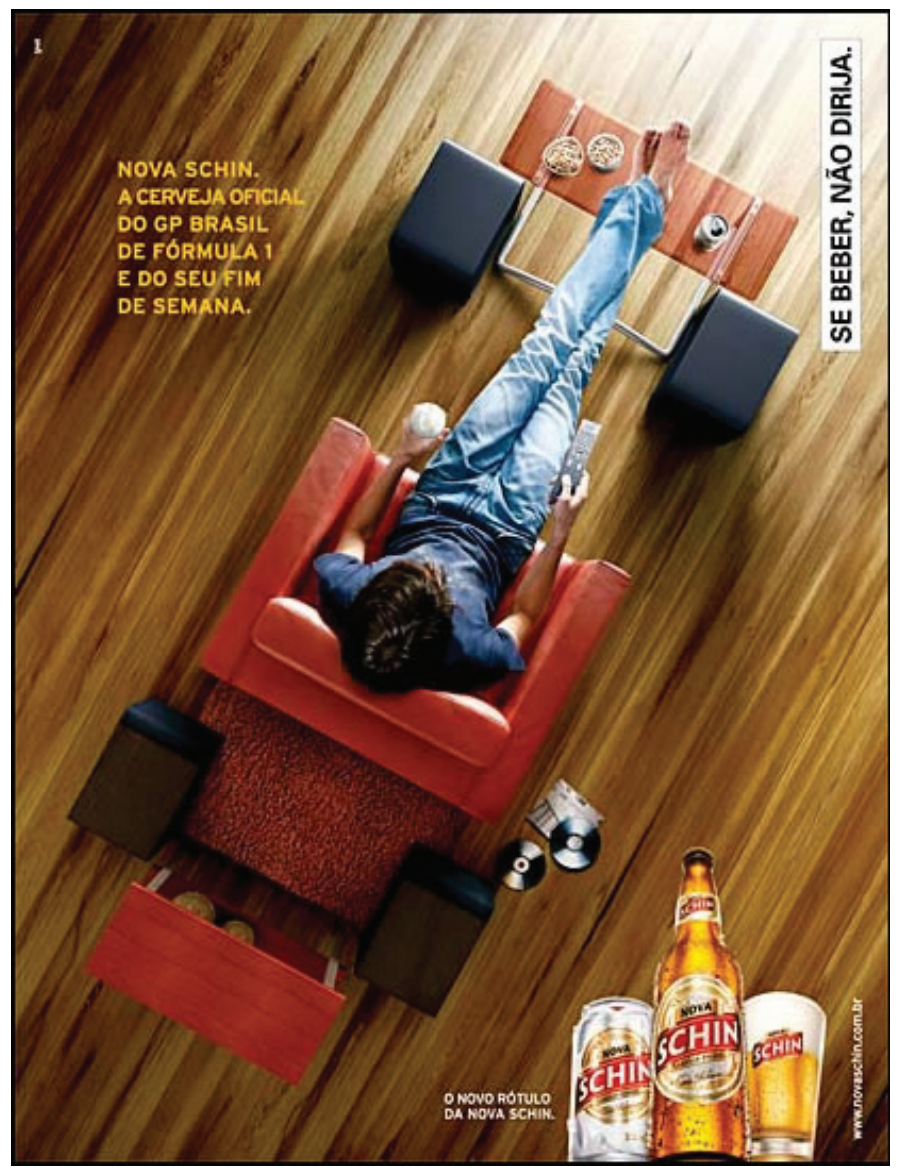

Figura 1 - Propaganda da Nova Schin veiculada na revista Veja, edição 2135, de 21/10/2009, p. 164 
Ao observar a propaganda publicitária, o leitor identifica um modelo masculino sentado em uma poltrona com os pés estendidos sobre uma mesinha, segurando na mão esquerda um copo de cerveja e, na mão direita, o controle remoto de um aparelho de áudio e/ou de vídeo. As duas mãos estão simetricamente dispostas, à esquerda e à direita, de tal forma que o foco em plongée da câmera que enquadra a cena faz crer que elas estão à mesma altura, como se estivessem segurando o volante de carro imaginário. Essa imagem ocupa a parte central de um campo de enquadramento retangular e a direção do olhar do homem sentado incide sobre o canto superior direito do retângulo, donde emana uma luminosidade mais intensa que vai se perdendo exatamente em direção ao canto oposto, qual seja, o esquerdo da parte inferior.

A cena captada pela foto constrói a imagem de um carro de fórmula 1. A mesinha dianteira sobre a qual o homem apoia os pés descalços é ladeada por duas caixas pretas que simulam os pneus do carro. Exatamente no mesmo ângulo e na mesma direção, duas outras caixas de som pretas estão dispostas na parte traseira da poltrona sobre a qual o homem está sentado, aparentando os outros dois pneus do carro. Entre a poltrona e outra mesinha localizada logo atrás dela há um tapete. A cor dessas três peças, a poltrona, o tapete e a mesinha traseira é a vermelha, o que dá forma a um conjunto monocromático. A disposição do modelo masculino, sentado sobre a poltrona vermelha com as pernas cruzadas e estendidas sobre a mesinha dianteira, configura o eixo do carro de corrida. Seu corpo é a representação do corpo do piloto e do corpo do carro de fórmula 1. Homem e máquina estão em simbiose, tal como é característico do esporte de fórmula 1.

A imagem descrita no parágrafo acima, num primeiro momento, pode parecer marcada pela estaticidade, pois os sentidos a ela agregados (poltrona, pés estendidos, contemplação) reforçam o estado de repouso. Ocorre, porém, que o foco em plongée da câmera fotográfica remete à captação das câmeras de televisão que filmam uma corrida de carros. E, nessa situação, os carros estão em movimento, pois estão em ação numa corrida. Os elementos que quebram essa estaticidade e dão movimento à foto são o isolamento dos objetos visualizados, pois eles não são ladeados por absolutamente nada, como se estivessem numa ampla sala vazia, e, principalmente, a imagem do assoalho sobre o qual os objetos estão dispostos. Trata-se de um assoalho de madeira, com tábuas em diagonal, na mesma direção em que estão os objetos que simulam o carro de fórmula 1 , que cria o efeito da velocidade de uma carro deslizando em uma pista de corrida.

O efeito estético da foto é o reflexo de uma práxis enunciativa que compõe um texto antitético. Ela retrata a confluência do estático e do dinâmico, do esporte de corrida de carros e do relaxamento do final de semana. É exatamente isso o que afirma o texto reproduzido em amarelo no canto superior esquerdo da 
foto: "NOVA SCHIN, A CERVEJA OFICIAL DO GP BRASIL DE FÓRMULA 1 E DOSEU FIM DE SEMANA". O modelo masculino que aparece na foto veste calça jeans, camiseta e está descalço, representando, dessa forma, a descontração, o lazer. Ele segura um copo de cerveja e, na mesa em que coloca seus pés, estão a lata aberta de Nova Schin e dois pratinhos de aperitivos; é a posição de relaxamento para ver a corrida que passa no aparelho de televisão, identificado pelo leitor da propaganda ao observar o ângulo superior direito iluminado da foto.

Nesse mesmo canto superior direito há a advertência para os riscos da ingestão de álcool quando se está conduzindo um veículo: "SE BEBER, NÃO DIRIJA". Disposta em linha vertical, oposta à da mensagem veiculada no canto superior esquerdo, a frase condicional imperativa, além de cumprir a lei que dispõe sobre as restrições ao uso e à propaganda de bebidas alcoólicas, reforça a antítese da foto. Embora o motorista esteja ingerindo bebida alcoólica, ele está em repouso, pois o movimento é uma ilusão.

A relação entre o enunciador e o enunciatário da propaganda é mediada pelo contrato veridictório da cena narrada, ao mesmo tempo em que o aspecto passional revela-se no apelo ao consumo, que é característico dos textos de propaganda. Nesse sentido, pode-se dizer que a práxis enunciativa constrói-se da mesma forma que no texto literário anteriormente examinado, embora o propósito do texto de propagada seja distinto do literário. A depreensão do sentido revelado pelo texto da propaganda está associada à identificação de um contexto que por ele é acionado. As corridas de carro normalmente acontecem nos finais de semana e é esse momento de descontração, de lazer, que está sendo reforçado pelo texto.

A prática semiótica revela que a veridicção e a paixão são elementos intrínsecos à constituição argumentativa dos textos. A mediação dos sentidos entre o enunciador e o enunciatário é sempre realizada por meio de uma negociação em que o aspecto tensivo é inerente. A instituição do parecer verdadeiro, próprio da veridicção, e a modalização do ser, própria da paixão, estão em constante movimento para que o ato de apreensão e de interpretação do texto se realize.

Os recursos veridictórios e passionais acionados pelo conto de Machado e pela propaganda da cerveja Nova Schin são idênticos, embora com propósitos distintos. Enquanto o primeiro se vale do recurso estético para manipular um leitor que valoriza positivamente o caráter literário do texto que lê, o segundo também se vale de uma estética visual para levar o leitor ao consumo do produto que é anunciado. A construção de uma representação de verdade tem o apelo passional como seu aliado. O conto ironiza uma paixão representada e aciona o dispositivo passional para 
conquistar seu leitor; a propaganda não encena a paixão, mas se vale do dispositivo passional para levar seu leitor à ação.

\section{Considerações finais}

O propósito deste texto consistiu, portanto, em mostrar os procedimentos da veridicção e da paixão presentes no discurso, enquanto resultado de um ato de enunciação, entendido como uma práxis. Retomando a referência a Hjelmslev inicialmente apresentada, é importante destacar que, tal como aponta Bertrand (2003), quando o autor dinamarquês propõe alterar a oposição saussuriana língua/fala para esquema/uso, ressalta o caráter estrutural do aparelho linguístico (língua) ao mesmo tempo em que chama atenção para as práticas envolvidas pelo uso dessa mesma língua, que são determinadas por "hábitos das comunidades linguísticas e culturais ao longo da história" (BERTRAND, 2003, p.86). Bertrand afirma ainda o seguinte sobre esse caráter social do discurso:

[...] É portanto a utilização da estrutura de significação que define o uso. Quer esta definição seja vista positivamente - quer negativamente - a partir das coerções e incompatibilidades semânticas impostas - em qualquer dos casos o uso 'designa a estrutura fechada pela história'. É assim que seus produtos resultam da práxis enunciativa. Podemos, pois, dizer que 'o cerceamento de nossa condição de homo loquens' se fundamenta em duas ordens de restrições que determinam a realização do discurso, as imposições a priori das categorias morfossintáxicas e os limites, de ordem sociocultural, impostos pelo hábito, pelas ritualizações, pelos esquemas, pelos gêneros, e até pela fraseologia, que moldam e modelam, sem que o saibamos, a previsibilidade e as expectativas de sentido. (BERTRAND, 2003, p. 86-7. grifos do autor)

Ao focalizar, portanto, a questão da enunciação, os conceitos de veridiç̧ão e de paixão têm importância uma vez que essa coerção histórica do discurso não anula o fato de que o ato comunicativo realizado por meio da linguagem é uma representação e que e que a linguagem age sobre o sujeito para quem esse ato comunicativo é dirigido. O que é historicamente determinante no discurso, como foi apontado acima, são os hábitos linguísticos e culturais de uma determinada comunidade linguística, mas isso não significa que seja possível uma relação transparente entre a verdade e o dizer.

$\mathrm{O}$ ato interpretativo apreende os sentidos veiculados pelo texto e ele constrói-se a partir de uma negociação instaurada entre o sujeito que o produz e o sujeito a quem se dirige. Mais do que isso, essas posições de subjetividade são também constructos do texto, uma vez que o enunciador e o enunciatário são instâncias constituintes da linguagem que entra em uso durante o processo comunicativo. A semiótica originária dos trabalhos de Greimas é uma perspectiva teórica que vem ao longo do tempo, desde que 
foi inicialmente proposta, procurando aprofundar o exame da constituição do sentido na linguagem.

\begin{abstract}
The aim of this paper is to show how the methodological apparatus of Greimasian semiotics is applied to tackle discourse issues. In particular, focusing on the concepts of veridiction and passion, two specific discourse procedures, it is examined how these concepts are included in the enunciative praxis by analyzing two distinct texts: the short story "O cônego ou a metafísica do estilo", by Machado de Assis, and the Nova Schin beer ad published in a Brazilian weekly magazine.
\end{abstract}

Keywords: Enunciation. Enunciative praxis. Passion. Text. Veridiction.

\title{
REFERÊNCIAS
}

ASSIS, Joaquim Maria Machado de. Obra completa. vol. II. Rio de Janeiro: Nova Aguilar, 1997.

AUTHIER-REVUZ, J. Palavras incertas: as não-coincidências do dizer. Trad. Claudia R. Castellanos Pfeiffer et al. Campinas, SP: Editora da UNICAMP, 1998.

BERTRAND, Denis. Caminhos da semiótica. Bauru, SP: EDUSC, 2003. CORTINA, Arnaldo. Duas leituras da paixão. CASA - Cadernos de Semiótica Aplicada. http://www.fclar.unesp.br/grup:, v.2, n.2, 2004.

GREIMAS, Algirdas Julien. Du sens II. Essais de sémiotique. Paris: Seuil, 1983.

GREIMAS, Algirdas Julien \& COURTÉS, Joseph. Dicionário de semiótica. Tradução de Alceu Dias Lima et al. São Paulo: Contexto, 2008.

FONTANILLE, Jacques. Semiótica do discurso. Tradução de Jean Cristtus Portela. São Paulo: Contexto, 2007.

GREIMAS, Algirdas Julien \& FONTANILLE, Jacques. Semiótica das paixões. Dos estados de coisas aos estados de alma. Tradução de Maria José Rodrigues Coracini. São Paulo: Ática, 1993.

HÉNAULT, Anne. História concisa da semiótica. Tradução de Marcos Marcionilo. São Paulo: Parábola Editorial, 2006.

HJELMSLEV, Louis. Prolegômenos a uma teoria da linguagem. Tradução de J. Teixeira Coelho Netto. São Paulo: Perspectiva, 1975.

LLOSA, Mario Vargas. A linguagem da paixão. Tradução de Wladir Dupont. São Paulo: Arx; 2002. 